ORIGINAL ARTICLE

\title{
Genetic changes in the RNA components of RNase MRP and RNase P in Schmid metaphyseal chondrodysplasia
}

\author{
M Ridanpää, L M Ward, S Rockas, M Särkioja, H Mäkelä, M Susic, F H Glorieux, W G Cole, \\ O Mäkitie
}

\author{
See end of article for \\ authors' affiliations \\ Correspondence to: \\ Dr O Mäkitie, Hospital for \\ Children and Adolescents, \\ University of Helsinki, PO \\ Box 281, FIN-00029 \\ Helsinki, Finland: \\ outi.makitie@helsinki.fi \\ Revised version received \\ 10 June 2003 \\ Accepted for publication \\ 10 June 2003
}

Background: The Schmid type of metaphyseal chondrodysplasia (MCDS) is generally due to mutations in COLIOA 1 encoding for type $\mathrm{X}$ collagen of cartilage.

Methods: We performed a study on the genes coding for the RNA components of RNase MRP (MRPR) and RNase $\mathrm{P}$ (HIRNA) among 20 patients with diagnosis of MCDS and no mutations in COLIOA1.

Results: Two patients were found to be homozygous for a base substitution $G$ for $A$ at nucleotide 70 of $R M R P$, which is the major mutation causing cartilage-hair hypoplasia. No pathogenic mutations were detected in HIRNA.

Conclusion: Cartilage-hair hypoplasia diagnosis should be considered in patients with metaphyseal chondrodysplasia even in the absence of any extra-skeletal manifestations if no mutation in COL1OAl can be found and the family history is compatible with autosomal recessive inheritance. Correct diagnosis is important for genetic counselling and for proper follow up of the patients.
T Schmid type of metaphyseal chondrodysplasia (MCDS, OMIM 156500) is characterised by short stature, bowed legs, coxa vara, and specific metaphyseal changes seen in radiographs. ${ }^{12}$ Autosomal dominant mutations in COL10A1 (OMIM \# 120110), which encodes for type X short chain non-fibrillar collagen of cartilage, have been identified in some patients with this phenotype. Most of the mutations reside in the carboxyterminal globular domain $(\mathrm{CNl})$ while two mutations are in a putative signal peptide cleavage site. ${ }^{3-8}$ Despite thorough mutation screening in COL1OAl, no mutations have been identified in a number of MCDS patients. ${ }^{9}{ }^{10}$

We have recently reported on 46 RMRP (OMIM \# 157660) mutations causing recessively inherited cartilage-hair hypoplasia (CHH, OMIM \# 250250), another type of metaphyseal chondrodysplasia. ${ }^{11}{ }^{12} \mathrm{CHH}$ is characterised clinically by short limbed short stature, hair hypoplasia, defective immunity, and haematological abnormalities, and radiographically by metaphyseal flaring and irregularity. ${ }^{13}{ }^{14}$ The untranslated $R M R P$ gene encodes the RNA component of the RNase mitochondrial RNA processing (MRP) complex. Normally, the RNase endoribonuclease MRP complex is involved in multiple cellular and mitochondrial functions but the functional impairment of the RMRP gene product that causes disease remains to be characterised. ${ }^{11}{ }^{15}$ Although MCDS and $\mathrm{CHH}$ are separate disorders, phenotypes and metaphyseal changes in radiographs can resemble each other. As mutations in the COL10Al gene explain only part of the MCDS cases, we first hypothesised that the RMRP genotype might play a role. In a search for $R M R P$ mutations in 20 patients with diagnosis of MCDS and no mutations in COL1OAl, we found two patients homozygous for the major mutation $70 \mathrm{~A} \rightarrow \mathrm{G}$. This finding has further initiated our screening in the same set of patients for mutations in HIRNA, a gene coding for the RNA component of RNase $\mathrm{P}$, another endoribonuclease, which is structurally and functionally similar to RNase MRP. ${ }^{15} 16$

\section{METHODS}

\section{Subjects and families}

As part of an ongoing research program on molecular mechanisms in skeletal dysplasias, which was approved by the Research Ethics Board of The Hospital for Sick Children, Toronto, Canada, DNA samples of 32 patients with the diagnosis of MCDS were studied for COL1OAl mutations. The diagnosis of MCDS was based clinically on short limbed short stature and absence of evident extra-skeletal manifestations (sparse hair, increased rate of infections, anaemia), and radiographically on compatible metaphyseal changes on skeletal radiographs. ${ }^{2}$ Causative mutations were identified in 12 patients ${ }^{6}$ (Susic \& Cole, unpublished data); the 20 patients with MCDS but no COL1OAl mutations were included in the present study. None of these patients had a positive family history of metaphyseal chondrodysplasia. Probands SMC3 and SMC44 carrying mutations in RMRP are described here in more detail.

\section{SMC3}

This male patient was born to healthy, consanguineous parents (father is mother's uncle) of white Canadian descent at 37 weeks of gestation with a birth length of $44 \mathrm{~cm}(<$ third percentile). The limbs were short, and skeletal radiographs at 10 months were consistent with a form of metaphyseal chondrodysplasia. Serum calcium, phosphate, and alkaline phosphatase levels were normal. The patient did not have anaemia, and a thorough immunological evaluation showed no evidence of cellular or humoral immune deficiency. At the age of 5 years, his height was $94 \mathrm{~cm}(<<$ third percentile) and he remained mildly disproportionate with relatively short limbs. There was no history of recurrent infections. His hair and nails were normal. There was no excessive ligamental laxity but there was mildly limited extension at the elbows and mild varus deformity of the legs. Radiographs at the age of 4 years showed generalised metaphyseal changes with flaring and irregularities; these changes were most marked in the knees and hips (fig 1). The fibula was excessively long distally relative to the tibia. The hand radiographs showed short metacarpals and phalanges, and the phalangeal

Abbreviations: $\mathrm{CHH}$, cartilage-hair hypoplasia; MCDS, Schmid type of metaphyseal chondrodysplasia; MRP, mitochondrial RNA processing endoribonuclease; SSCP, single strand conformation polymorphism 

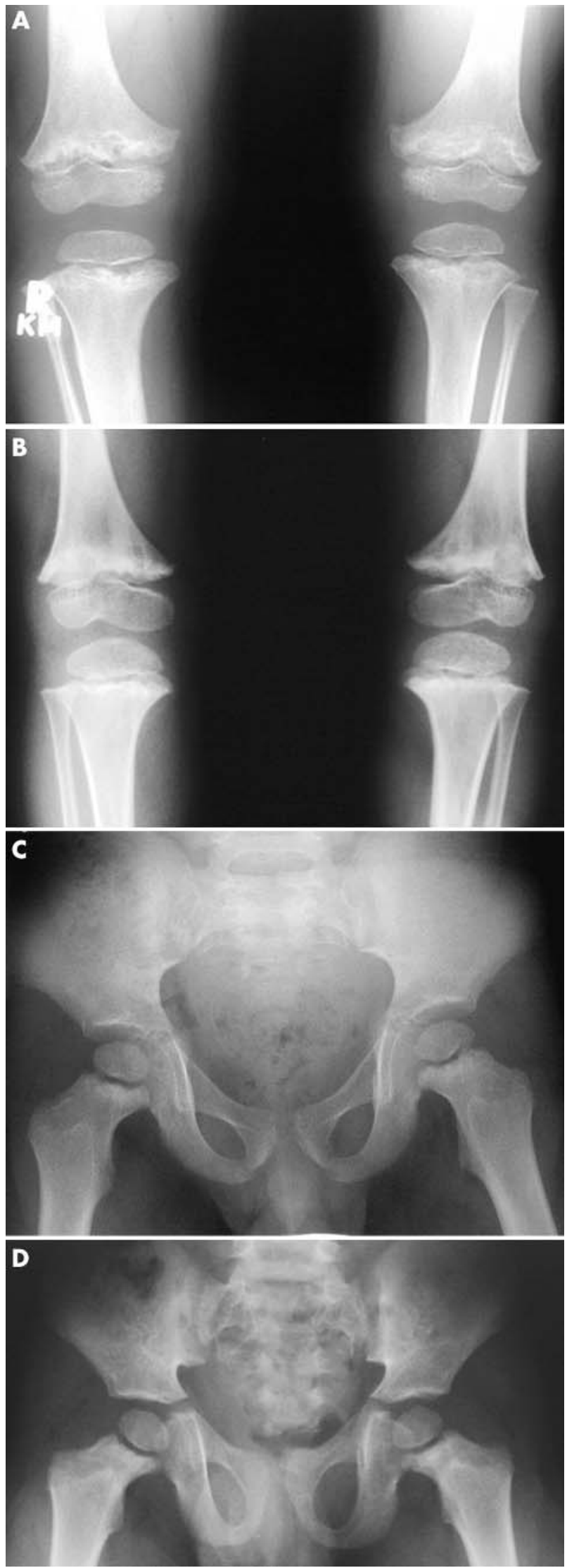

Figure 1 Radiographic findings in the two patients $\operatorname{SMC} 3(A, C)$ and SMC44 (B, D) with homozygous 70A $\rightarrow G$ mutations in the RMRP gene. Anteroposterior views of the knees $(A, B)$ and hips $(C, D)$ show metaphyseal flaring and irregularity. The changes are more marked in the knees than in the hips. epiphyses were small, but normal in shape. The vertebral bodies showed mild, non-specific changes.

\section{SMC44}

This 5 year old male patient was the second child born to healthy, non-consanguineous French-Canadian parents. A skeletal dysplasia was suspected at 32 weeks of gestation when an ultrasound revealed foreshortening of the extremities. He was born at 39 weeks of gestation with a birth weight of $3040 \mathrm{~g}$ (25th percentile) and birth length $44 \mathrm{~cm}(<$ third percentile). Metaphyseal chondrodysplasia was diagnosed soon after birth based on radiographic findings. The patient thrived in the post-natal period, although he developed pneumonia at 1 month of age, which required hospitalisation and treatment with intravenous antibiotics, to which he responded well. He had two further episodes of pneumonia (at 9 months and 5 years) as well as occasional bouts of otitis media, all of which necessitated treatment with oral antibiotics. At 2 years of age he contracted varicella, which followed a typical, uncomplicated course. He did not have difficulty tolerating standard vaccines. There was no history of constipation. The most recent evaluation of the patient at 5.6 years of age revealed a developmentally normal child in a good health without functional limitations (fig 2). The height was $90 \mathrm{~cm}$ and weight $14.5 \mathrm{~kg}$ (both well below the third percentile). The hair, eyelashes, and eyebrows appeared normal. The hands and feet were short and wide. There was a pectus carinatum, incomplete extension at the elbows,

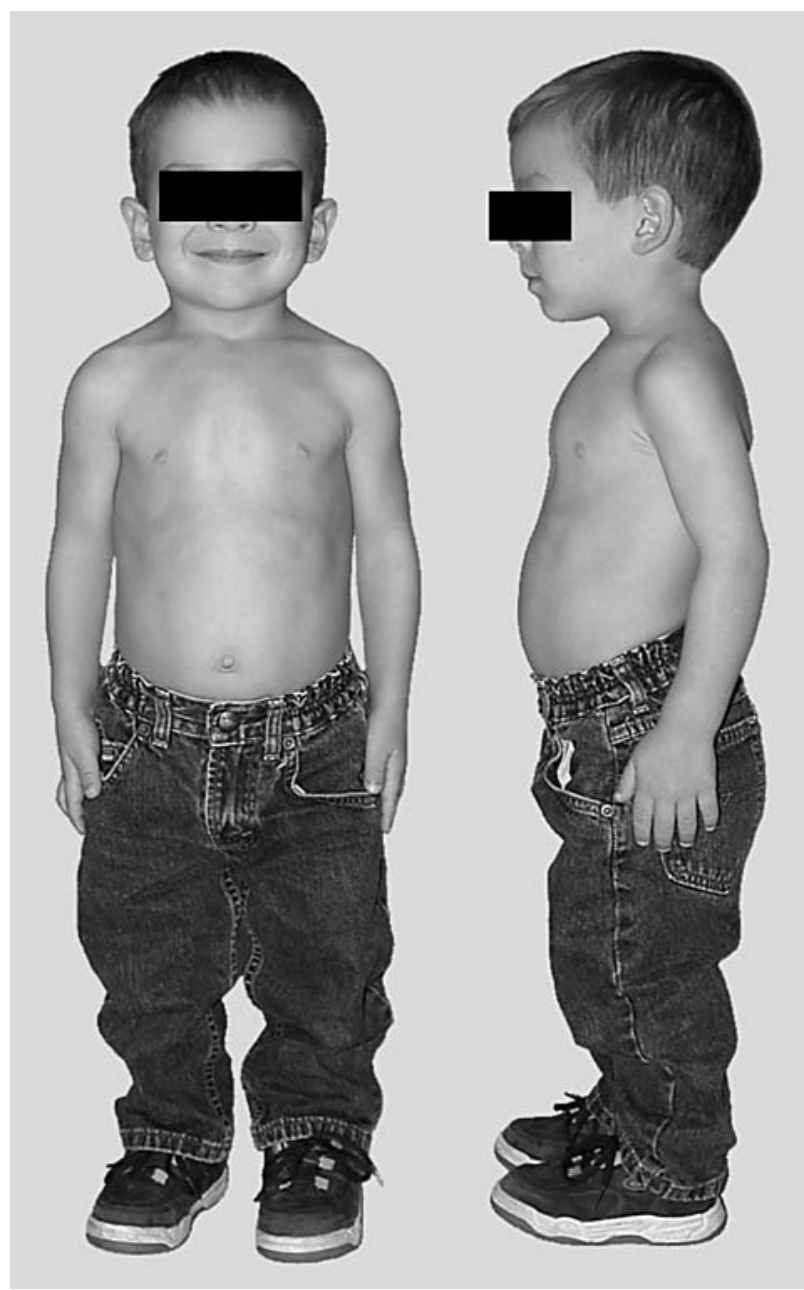

Figure 2 Patient SMC44 at 5 years of age. He has short limbed short stature with short fingers and no obvious hair hypoplasia. 
and mild hyperlaxity at the wrists and fingers. The spine was straight and skull shape was normal. A comprehensive haematological evaluation revealed a normal complete blood count and normal IgA, IgG, IgM, and IgE levels. Lymphocyte sub-populations were within the reference ranges, and mitogen induced lymphocyte stimulation tests were normal. Biochemical parameters of bone and mineral metabolism were unremarkable. A skeletal survey revealed multiple abnormalities, including shortening of the tubular bones, and widening and irregularity of the upper and lower extremity metaphyses (fig 1). The metaphyseal changes were most marked in the lower extremities. The fibula was excessively long distally relative to the tibia. The hand radiographs showed short metacarpals and phalanges, and multiple trapezoid shaped phalangeal epiphyses. The spine and skull were normal.

\section{Controls}

Fragment HlA was sequenced in DNA samples from 25 unrelated controls from The Centre d'Etude du Polymorphisme Humain (CEPH). In addition, 64 unrelated CEPH samples and samples from 34 unrelated controls from Europe, the Near East, and North and South America were studied using single strand conformation polymorphism (SSCP) analysis for the base pair change $\mathrm{G} \rightarrow \mathrm{A}$ at nucleotide (nt) 129.

\section{Mutation detection in RMRP}

Insertions and deletions in the promoter region were screened using PCR primers RM3IF and RM3IR as described previously. ${ }^{12}$ The major mutation (A70G) in cartilage-hair hypoplasia was detected on SSCP gels following PCR with primers RM70F and RM70R. ${ }^{12}$ In order to confirm SSCP findings and to detect other possible sequence changes, all DNA samples were sequenced. The promoter region was amplified using primers RM3F and RM3R, and the transcript was amplified using RMF and RMR. ${ }^{12}$ PCR products were purified using Qiagen Gel Extraction Kit (Qiagen GmbH,
Hilden, Germany) prior to automated sequencing (ABI3100 Sequencer; Applied Biosystems, Foster City, CA, USA).

\section{Mutation detection in HIRNA}

The promoter and the transcript (341 nts) of HIRNA (GenBank accession no. AL355075, X16612) were amplified in two overlapping fragments using primers HIAF 5'CCTGCAATATTTGCATGTCG-3'; HIAR 5'-AATGGGCGGA GGAGAGTAGT-3'; HIBF 5'-CCGGAGCTTGGAACAGACT-3'; and HIBR 5'-CCTCTGTTCCCAAAGGGTTT-3'. The PCR products were $446 \mathrm{bp}$ and $407 \mathrm{bp}$ (corresponding to nts -105 to +341 and +234 to +743 ), respectively. SSCP was performed on $0.7 \times$ MDE (FMC BioProducts, Rockland, ME, USA) gels at room temperature and $5 \mathrm{~W}$ for $20 \mathrm{~h}$. A large number of band patterns were detected and thus, 25 samples still available were re-amplified using the same primers. The PCR products were purified and sequenced as described above.

\section{RESULTS}

In the search for $R M R P$ mutations among 20 patients with diagnosis of MCDS, we found two probands, SMC3 and SMC44, to be homozygous for a base change $A \rightarrow G$ at nt 70 . This mutation is the worldwide major mutation causing CHH. $^{12}$ DNA samples from parents of SMC3 were available and both were found to be heterozygous for $70 \mathrm{~A} \rightarrow \mathrm{G}$, thus showing recessive inheritance. Clinically, SMC3 had short limbed short stature with no extra-skeletal features suggestive of $\mathrm{CHH}$. This latter diagnosis had been clinically excluded on the basis of normal hair, normal ligamental laxity and normal history of infections with normal immunological and haematological findings, even though the family history of consanguinity was suggestive of an autosomal recessive rather than dominant condition. The radiographic findings were consistent with metaphyseal chondrodysplasia. The only extra-skeletal manifestation of $\mathrm{CHH}$ demonstrated by patient SMC44 was mild joint laxity. All other CHH features, aside from the radiographic changes, were absent. He had a history of recurrent respiratory infections and otitis media, but their frequency was in keeping with the normal rate of

\begin{tabular}{|c|c|c|c|c|c|c|}
\hline \multirow[b]{2}{*}{ Sample } & \multirow[b]{2}{*}{ Status } & \multicolumn{5}{|c|}{ All changes in HIRNA† } \\
\hline & & $\mathrm{Nt}-18$ & $\mathrm{Nt}-8$ & $\mathrm{Ni}-7$ & Nt 129 & Other \\
\hline SMCl & Patient & $\mathrm{A} / \mathrm{G}$ & - & - & - & - \\
\hline \multirow[t]{2}{*}{ SMC3 } & Patient & $\mathrm{A} / \mathrm{G}$ & - & $C / G$ & - & - \\
\hline & Father of SMC3 & $A / G$ & - & - & - & - \\
\hline \multirow[t]{3}{*}{ SMC4 } & Patient & $A / G$ & $T / C$ & $C / G$ & $G / A$ & - \\
\hline & Mother of SMC4 & $\mathrm{G} / \mathrm{G}$ & $\mathrm{T} / \mathrm{C}$ & - & $\mathrm{G} / \mathrm{A}$ & - \\
\hline & Father of SMC4 & $A / G$ & $\mathrm{~T} / \mathrm{C}$ & $C / G$ & & - \\
\hline SMCl1 & Patient & $\mathrm{G} / \mathrm{G}$ & $\mathrm{T} / \mathrm{C}$ & - & $G / A$ & - \\
\hline \multirow[t]{3}{*}{$\mathrm{SMC12}$} & Patient & & - & - & - & Wild type \\
\hline & Father of $\mathrm{SMCl} 2$ & $A / G$ & - & - & - & - \\
\hline & Mother of SMCl2 & - & - & $C / G$ & - & - \\
\hline SMCl5 & Patient & & - & $\mathrm{C} / \mathrm{T}$ & - & - \\
\hline SMC20 & Patient & $A / G$ & - & - & - & - \\
\hline SMC23 & Patient & & - & - & - & Wild type \\
\hline SMC29 & Patient & $A / G$ & $T / C$ & - & $\mathrm{G} / \mathrm{A}$ & - \\
\hline SMC32 & Patient & $\mathrm{G} / \mathrm{G}$ & $\mathrm{T} / \mathrm{C}$ & - & - & $\mathrm{A} / \mathrm{G}$ at $-34, \mathrm{C} / \mathrm{T}$ at -9 \\
\hline SMC33 & Patient & $A / G$ & - & - & - & - \\
\hline SMC34 & Patient & $\mathrm{A} / \mathrm{G}$ & - & $C / G$ & - & - \\
\hline SMC40 & Patient & & - & $C / G$ & - & - \\
\hline SMC41 & Patient & $A / G$ & & - & - & - \\
\hline SMC42 & Patient & $A / G$ & $T / C$ & - & - & $\mathrm{A} / \mathrm{G}$ at $-34, \mathrm{C} / \mathrm{T}$ at -9 \\
\hline SMC44 & Patient & $A / G$ & $\mathrm{~T} / \mathrm{C}$ & - & $\mathrm{G} / \mathrm{A}$ & \\
\hline SMC45 & Patient & & $\mathrm{T} / \mathrm{C}$ & - & $\mathrm{G} / \mathrm{A}$ & $\mathrm{G} / \mathrm{G}$ at -34 \\
\hline SMC46 & Patient & $A / G$ & - & - & - & - \\
\hline SMC47 & Patient & & - & - & - & wt \\
\hline SMC48 & Patient & $G / G$ & - & & - & - \\
\hline Controls & - & A/G & $\mathrm{T} / \mathrm{C}$ & $\mathrm{C} / \mathrm{G} / \mathrm{T}$ & G/A & - \\
\hline
\end{tabular}

†HIRNA sequence in $\mathrm{X} 16612$ was used as a reference. 
Table 2 Clinical features in Schmid type of metaphyseal chondrodysplasia (MCDS) and cartilage-hair hypoplasia (CHH)

\begin{tabular}{lll}
\hline Feature & MCDS & CHH \\
\hline Skeletal findings & & \\
Growth failure & & + \\
Neonatal onset & - & + \\
Progressive & ++ & + \\
Disproportionate (short limbs) & ++ & $110-140 \mathrm{~cm}$ \\
Adult height & $130-145 \mathrm{~cm}$ & + \\
Bow legs & ++ & + \\
Increased joint laxity & - & + \\
Extra-skeletal findings & & + \\
Sparse hair & - & + \\
Immunodeficiency & - & + \\
Anaemia and macrocytosis & - & + \\
Increased risk of malignancy & - & Autosomal \\
Hirchsprung disease & - & recessive \\
Genetics & & \\
Mode of inheritance & Autosomal & \\
Responsible gene & dominant & \\
\hline ++, always present; + , often present;,- absent. &
\end{tabular}

infections in the first few years of life. Similar to patient SMC3, a comprehensive immunological and haematological investigation was normal. Furthermore, additional co-morbid conditions, such as Hirschprung's disease and gastrointestinal malabsorption, were not present in either patient.
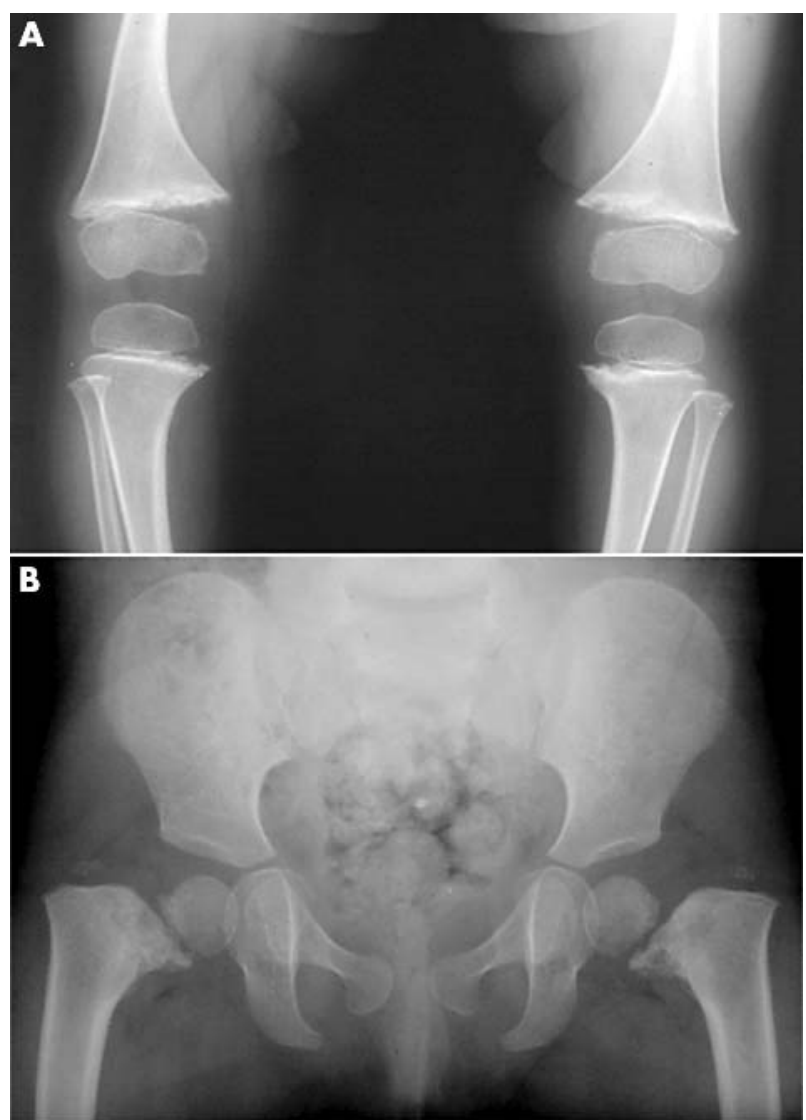

Figure 3 Radiographic findings in a 2.5 year old patient with MCDS and a heterozygous premature termination mutation $1952 \mathrm{G} \rightarrow \mathrm{A}$ in the COLIOAl gene. Anterior-posterior views of the knees (A) and hips (B) show metaphyseal flaring and irregularity, which is more marked in the hips than in the knees. The proximal femurs (B) show significant coxa vara deformity, vertical growth plate, and enlarged capital femoral epiphyses.
All genomic changes found in the transcript and the promoter region up to $\mathrm{nt}-47$ of HIRNA are listed in table 1 . A heterozygous base change $(G \rightarrow A)$ at nt129 resides in the transcript and was found in five patients and in one healthy mother. One of these patients (SMC44) was homozygous for $\mathrm{G} / \mathrm{G}$ at nt70 in RMRP. A base change $\mathrm{A} \rightarrow \mathrm{G}$ at $\mathrm{nt}-34$ was detected as homozygosity in one patient and as heterozygosity in two patients. This nucleotide resides only four nucleotides upstream from the TATA box of HIRNA. The other changes were all base substitutions in the region between the TATA box and transcription initiation site (nts $-7,-8,-9$, and -18 ; table 1 ).

All these aforementioned changes were found in the controls also. Among the 25 sequenced CEPH controls, base substitutions were found at sites $-7,-8,-9,-18$, and -34 in six, six, two, 11, and three samples, respectively (table 1). As new polymorphisms, changes $\mathrm{T} \rightarrow \mathrm{A}$ and $\mathrm{T} \rightarrow \mathrm{C}$ at $\mathrm{nt}-4$ were detected (T/A/C: 48/1/1). The significance and frequency of such three nucleotide polymorphisms within the non-coding sequence, observed also at nt -7 in the patients (table 1 ), remains unclear. The $129 \mathrm{G} \rightarrow$ A change in the transcript was found in seven of 123 control samples, and although nt 129 is evolutionarily conserved, ${ }^{17}$ we consider all these changes as polymorphisms because of their frequent occurrence also in the controls. In addition, in the controls a new base substitution was found once in HIRNA at evolutionarily conserved nts 73, 125, and 239. ${ }^{17}$ Based on our data, it is not possible to determine if these changes were rare polymorphisms or pathogenic mutations

\section{DISCUSSION}

Mutations in COL1OAI cause Schmid type metaphyseal chondrodysplasia, and although mutations in many collagen genes can cause more than one disease entity, mutations in COL $10 A 1$ have only been reported in MCDS. ${ }^{9}$ As no mutations have been identified in a large number of MCDS cases, we performed a study on the genes coding for the RNA components of RNase MRP and RNase P. These enzymes are structurally related, share the same protein components, show nuclear localisation, and function in similar processes..$^{15}$

Mutations in $R M R P$, the gene coding for the RNA component of RNase MRP, cause CHH. ${ }^{11}$ In a set of 20 patients with a diagnosis of MCDS without COL10Al mutations, we found two patients homozygous for the $70 \mathrm{~A} \rightarrow \mathrm{G}$ change in $R M R P$, the worldwide major mutation in $\mathrm{CHH}{ }^{12}$ Parents' samples were available for mutation detection in one case; both parents were found to be heterozygous carriers for $70 \mathrm{~A} \rightarrow \mathrm{G}$. Different from the autosomal dominant inheritance of MCDS, this is consistent with an autosomal recessive mode of inheritance as in $\mathrm{CHH}$.

Phenotypic variability in $\mathrm{CHH}$ is remarkable, even within sibships. ${ }^{14}$ It has been suggested that patients with radiographic findings consistent with $\mathrm{CHH}$ but without apparent hair hypoplasia have a variant form of $\mathrm{CHH} .{ }^{18}$ However, based on the results of the present study and some previous reports, ${ }^{19}$ it is more likely that such patients represent the mild end of the spectrum of clinical severity. Therefore, $\mathrm{CHH}$ cannot be excluded based on the absence of extra-skeletal manifestations. Other clinical features, such as age at onset of growth failure, can be used in differentiating $\mathrm{CHH}$ clinically from MCDS (table 2). In CHH the growth failure is usually already present at birth and always during the first year of life, as was seen also in both patients in this study, whereas in MCDS short stature is seldom the presenting feature and is not present during the first year of life. ${ }^{214}$ Although radiographic metaphyseal changes are present in both conditions, they differ in severity and distribution (figs 1 and 3). In $\mathrm{CHH}$ the metaphyseal changes are most prominent at the knees, 
with significant flaring and irregularity of the metaphyses. ${ }^{13}$ The proximal femurs and other long bones are affected but to a lesser extent. Hand radiographs show short metacarpals and phalanges with metaphyseal irregularity and, especially in older children, cone shaped epiphyses. ${ }^{19}$ In MCDS, the radiographic changes are most severe at the hips with enlarged capital femoral epiphyses, short femoral neck with significant metaphyseal irregularity, and severe coxa vara deformity with vertically oriented growth plate (fig 3 ). ${ }^{2}$ The metaphyseal changes are marked also at the knees with irregular, thickened, and widened appearance of the growth plates. Hand radiographs are normal. ${ }^{2}$

In patients with MCDS but no mutation in COL1OAl, screening for mutations in the RMRP gene is recommended. Differentiating $\mathrm{CHH}$ from MCDS has important clinical implications. It is not known whether patients with $R M R P$ mutations but no extra-skeletal manifestations of $\mathrm{CHH}$ are at a similarly increased risk of malignancies as patients with phenotypically phenotypically usual $\mathrm{CHH}^{20}$ However, our previous studies have shown that the risk of malignancies cannot be predicted on the basis of immunological parameters in an individual patient. ${ }^{21}$ Therefore, life long follow up of all patients with metaphyseal chondrodysplasia and RMRP mutations, irrespective of their phenotypic presentation, is recommended. In addition, appropriate genetic counselling is not possible without proper DNA diagnosis when the family history does not confirm dominant inheritance.

RNase $\mathrm{P}$ is an endoribonuclease, the function of which is related to that of RNase MRP. ${ }^{16}$ Owing to the many similarities between RNase MRP and RNase P, and the $R M R P$ mutations in two patients in this set of MCDS cases, we also sequenced HIRNA, the gene coding for the RNA component of RNase P. The structure of HIRNA is very similar to that of RMRP. As $\mathrm{CHH}$ results from mutations either in the RMRP transcript or those that change the distance between the TATA box and transcription initiation site of $R M R P{ }^{11}$ we sequenced the corresponding regions of $H I R N A$. Altogether, base substitution polymorphisms were found at six sites in the patients and controls upstream from the transcription initiation site. We also detected a frequent base substitution polymorphism $129 \mathrm{G} \rightarrow \mathrm{A}$ in the transcript. Finally, three controls harboured a base substitution at one of the conserved nucleotides of HIRNA; a rare polymorphism or mutation could not be excluded in these cases. Mutations in the RNA components and proteins of RNase MRP and RNase $P$ cause altered growth phenotypes in yeast. ${ }^{22-28}$ In humans, only mutations in $R M R P$ have been characterised and the possible role of the RNase P RNA and the protein components of these endoribonucleases in diseases remain open for investigation.

In conclusion, our study suggests that MCDS and $\mathrm{CHH}$ may be challenging to distinguish on clinical and radiological grounds. If there is a family history consistent with an autosomal dominant condition, $\mathrm{CHH}$ as a cause of the metaphyseal chondrodysplasia can usually be excluded. If no such family history is present and if no mutation in COL1OAI is found, a diagnosis of $\mathrm{CHH}$ should be considered for patients presenting with a metaphyseal chondrodysplasia, even in the absence of extra-skeletal manifestations of the disease. The importance of specific diagnosis is highlighted by the need for appropriate genetic counselling and for proper follow up of the patients. This study showed no conclusive evidence for causative mutations in HIRNA in patients with metaphyseal chondrodysplasia, therefore, the role of this gene in skeletal dysplasias remains unclear.

\section{ACKNOWLEDGEMENTS}

This study was financially supported by The March of Dimes Birth Defects Foundation (\#6-FY00-294), Helsinki University's Research
Funds, and the Helsinki University Central Hospital (to M Ridanpää); by the Shriners of North America (to L Ward and F H Glorieux); by a grant from the Canadian Institutes of Health Research (to W G Cole); and by the Foundation for Paediatric Research, Helsinki, Finland and by a European Society for Paediatric Endocrinology Research Fellowship, sponsored by Novo Nordisk A/S (to O Mäkitie).

\section{Authors' affiliations}

M Ridanpää, S Rockas, M Särkioja, H Mäkelä, Folkhälsan Institute of Genetics and Department of Medical Genetics, Biomedicum Helsinki,

FI-00014 University of Helsinki

L M Ward, Department of Pediatrics, University of Ottawa, Ottawa, Ontario, Canada

F H Glorieux, Genetics Unit, Shriners Hospital for Children, McGill University, Montreal, Quebec, Canada

M Susic, W G Cole, O Mäkitie, Centre for the Study of Heritable Connective Tissue Diseases, Research Institute, University of Toronto, Toronto, Ontario, Canada

O Mäkitie, Hospital for Children and Adolescents, Fl-00029 Helsinki University Central Hospital, Finland

\section{REFERENCES}

1 Schmid F. Beitrag zur Dysostosis enchondralis metaphysaria. Monatsschr Kinderheilk 1949.97:393.

2 Lachman RS, Rimoin DL, Spranger J. Metaphyseal chondrodysplasia, Schmid type. Clinical and radiographic delineation with a review of the literature. Pediatr Radiol 1988; 18:93-102.

3 Warman ML, Abbott M, Apte SS, Hefferon T, Mclntosh I, Cohn DH, Hecht JT, Olsen BR, Francomano CA. A type $X$ collagen mutation causes Schmid metaphyseal chondrodysplasia. Nat Genet 1993;5:79-82.

4 Wallis GA, Rash B, Sykes B, Bonaventure J, Maroteaux P, Zabel B, WynneDavies R, Grant ME, Boot-Handford RP. Mutations within the gene encoding the alpha $1(X)$ chain of type $X$ collagen (COL10A1) cause metaphyseal chondrodysplasia type Schmid but not several other forms of metaphyseal chondrodysplasia. J Med Genet 1996;33:450-7.

5 Ikegawa S, Nakamura K, Nagano A, Haga N, Nakamura Y. Mutations in the $\mathrm{N}$-terminal globular domain of the type $\mathrm{X}$ collagen gene (COL1OA1) in patients with Schmid metaphyseal chondrodysplasia. Hum Mutat 1997;9:131-5

6 Chan D, Jacenko $O$. Phenotypic and biochemical consequences of collagen $X$ mutations in mice and humans. Matrix Biol 1998;17:169-84.

7 Sawai H, Ida A, Nakata Y, Koyama K. Novel missense mutation resulting in the substitution of tyrosine by cysteine at codon 597 of the type $X$ collagen gene associated with Schmid metaphyseal chondrodysplasia. J Hum Genet 1998:43:259-61.

8 Gregory CA, Zabel B, Grant ME, Boot-Handford RP, Wallis GA. Equal expression of type $X$ collagen mRNA from mutant and wild type COL1OA1 alleles in growth plate cartilage from a patient with metaphyseal chondrodysplasia type Schmid. J Med Genet 2000:37:627-9.

9 Kuivaniemi H, Tromp G, Prockop DJ. Mutations in fibrillar collagens (types I, II, III, and XI), fibril-associated collagen (type IX), and network-forming collagen (type X) cause a spectrum of diseases of bone, cartilage, and blood vessels. Hum Mutat 1997:9:300-15.

10 Ikegawa S, Nishimura G, Nagai T, Hasegawa T, Ohashi H, Nakamura Y Mutation of the type $X$ collagen gene (COL1OA1) causes spondylometaphyseal dysplasia. Am J Hum Genet 1998;63:1659-62.

11 Ridanpää M, van Eenennaam H, Pelin K, Chadwick R, Johnson C, Yuan B, vanVenrooii W, Pruijn G, Salmela R, Rockas S, Mäkitie O Kaitila I, de la Chapelle A. Mutations in the RNA component of RNase MRP cause a pleiotropic human disease, cartilage-hair hypoplasia. Cell 2001;104: 195-203.

12 Ridanpää M, Sistonen P, Rockas S, Rimoin DL, Mäkitie O, Kaitila I. Worldwide mutation spectrum in cartilage-hair hypoplasia: ancient founder origin of the major $70 \mathrm{~A} \rightarrow \mathrm{G}$ mutation of the untranslated RMRP. Eur J Hum Genet 2002; 10:439-47

13 Mäkitie O, Sulisalo T, de la Chapelle A, Kaitila I. Cartilage-hair hypoplasia. J Med Genet 1995;32:39-43.

14 Mäkitie O, Kaitila I. Cartilage-hair hypoplasia - clinical manifestations in 108 Finnish patients. Eur J Pediatr 1993;152:211-17.

15 van Eenennaam H, Jarrous N, van Venrooij WJ, Pruijn GJ. Architecture and function of the human endonucleases RNase $\mathrm{P}$ and RNase MRP. IUBMB Life 2000;49:265-72.

16 Jarrous $N$. Human ribonuclease P: subunits, function, and intranuclear localization. RNA 2002:8:1-7.

17 Sbisà $E$, Pesole G, Tullo A, Saccone C. The evolution of the RNase P- and RNase MRP-associated RNAs: phylogenetic analysis and nucleotide substitution rate. J Mol Evol 1996;43:46-57.

18 Verloes A, Pierard GE, Le Merrer M, Maroteaux P. Recessive metaphyseal dysplasia without hypotrichosis. A syndrome clinically distinct from McKusick cartilage-hair hypoplasia. J Med Genet 1990;27:693-6.

19 Bonafé L, Schmitt K, Eich G, Giedion A, Superti-Furga A. RMRP gene sequence analysis confirms a cartilage-hair hypoplasia variant with only skeletal manifestations and reveals a high density of single-nucleotide polymorphisms. Clin Genet 2002;61:146-51. 
20 Mäkitie O Pukkala E, Teppo L, Kaitila I. Increased incidence of cancer in patients with cartilage-hair hypoplasia. J Pediatr 1999;134:315-18.

21 Mäkitie O, Kaitila I, Savilahti E. Susceptibility to infections and in vitro immune functions in cartilage-hair hypoplasia. Eur J Pediatr 1998;157:816-20.

22 Lygerou Z, Mitchell P, Peffalski E, Seraphin B, Tollervey D. The POP1 gene encodes a protein component common to the RNase MRP and RNase P ribonucleoproteins. Genes 1994;8:1423-33.

23 Dichtl B, Tollervey D. Pop3p is essential for the activity of the RNase MRP and RNase P ribonucleoproteins in vivo. EMBO J 1997:16:417-29.

24 Cai T, Reilly TR, Cerio M, Schmitt ME. Mutagenesis of SNM1, which encodes a protein component of the yeast RNase MRP, reveals a role for this ribonucleoprotein endoribonuclease in plasmid segregation. Mol Cell Biol $1999 ; 19: 7857-69$
25 Shadel GS, Buckenmeyer GA, Clayton DA, Schmitt ME, Mutational analysis of the RNA component of Saccharomyces cerevisiae RNase MRP reveals distinct nuclear phenotypes. Gene 2000;245: 175-84.

26 Pagan-Ramos E, Lee Y, Engelke DR. Mutational analysis of Saccharomyces cerevisiae nuclear RNase $P$ : randomization of universally conserved positions in the RNA subunit. RNA 1996;2:441-51.

27 Chamberlain JR, Pagan-Ramos, Kindelberger DW, Engelke DR. An RNase P RNA subunit mutation affects ribosomal RNA processing. Nucleic Acids Res 1996;24:3158-66.

28 Ziehler WA, Morris J, Scott FH, Millikin C, Engelke DR. An essential protein-binding domain of nuclear RNase P RNA. RNA 2001; 7:565-75.

\section{$\mathrm{ECHO}$}

\section{Transplanting CY282 heterozygous livers is risky}

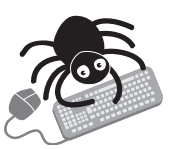

Please visit the Journal of

Medical

Genetics website [www. imedgenet.com] for a link to the full text of this article. ore safeguards may be needed in liver transplantation, after the discovery of a new $M$ mutation in a recipient sparking iron overload. This seemingly rare event questions the supposed suitability of donor livers heterozygous for the $C 282 Y$ gene-the commonest type transplanted.

The case centred on iron overload detected in a liver biopsy specimen taken from a recipient four years after transplantation during a hernia repair. Hepatic iron concentration (HIC) was way above normal and hepatic iron index (HII) indicated hereditary haemochromatosis. Yet the recipient did not have the condition before transplantation and was negative for HFE mutations C282Y and H63D. The donor was heterozygous for the C282Y gene and had only mild iron stores in the liver.

Sequencing of the HFE gene disclosed single base heterozygosity in exon 1 g.189G $\rightarrow$ C, causing serine substitution at codon $6(R 6 S)$ in the recipient, and $C 282 Y$ heterozygosity in the donor. Two thirds of the recipient's living relatives were heterozygous for R6S but not C282Y or $H 63 D$ mutation; none showed iron overload. Thirty five European controls without hereditary haemochromatosis tested negative for the R6G mutation. The authors propose an interaction between $R 6 S$ and $C 282 Y$ mutations to explain the events.

The donor was a 46 year old woman with HIC and HII values within the normal range and the recipient a 34 year old man with cirrhosis of the liver from alcohol misuse Both were Caucasian.

Transplantation of livers heterozygous for $C 282 Y$ is widespread, but this discovery casts doubt on safety.

$\Delta$ Gut 2003;52:433-435. 